\title{
A computational model to predict the Diels-Alder reactivity of aryl/alkyl-substituted tetrazines
}

\author{
Dennis Svatunek $^{1} \cdot{\text { Christoph } \text { Denk }^{1} \cdot \text { Hannes Mikula }}^{1}$ (I)
}

Received: 18 October 2017/Accepted: 20 November 2017/Published online: 29 November 2017

(c) The Author(s) 2017. This article is an open access publication

\begin{abstract}
The tetrazine ligation is one of the fastest bioorthogonal ligations and plays a pivotal role in timecritical in vitro and in vivo applications. However, prediction of the reactivity of tetrazines in inverse electron demand Diels-Alder-initiated ligation reactions is not straight-forward. Commonly used tools such as frontier molecular orbital theory only give qualitative and often even wrong results. Applying density functional theory, we have been able to develop a simple computational method for the prediction of the reactivity of aryl/alkyl-substituted tetrazines in inverse electron demand Diels-Alder reactions.
\end{abstract}

\section{Graphical Abstract}

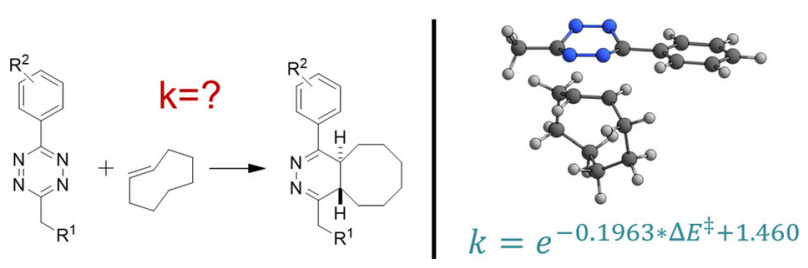

Keywords Cycloadditions - Computational chemistry · Click chemistry $\cdot$ Bioorthogonal chemistry

Electronic supplementary material The online version of this article (https://doi.org/10.1007/s00706-017-2110-x) contains supplementary material, which is available to authorized users.

Hannes Mikula

hannes.mikula@tuwien.ac.at

1 Institute of Applied Synthetic Chemistry, TU Wien, Vienna, Austria

\section{Introduction}

Tetrazine ligations (TLs) are bioorthogonal inverse electron demand Diels-Alder (IEDDA) initiated cycloadditions proceeding with exceptional high second-order rates of up to 3,300,000 $\mathrm{M}^{-1} \mathrm{~s}^{-1}$ [1]. In TLs, an 1,2,4,5-tetrazine (Tz) reacts with an electron-rich dienophile in an IEDDA reaction followed by cycloreversion under the loss of nitrogen (Fig. 1). Strained alkenes such as norbornenes [2,3], cyclopropenes [4, 5], and trans-cyclooctenes (TCOs) [1, 6-8] are commonly used dienophiles, with TCOs providing the highest reactivity. The rate-determining step is the Diels-Alder cycloaddition, while the cycloreversion has only a low energy barrier and is suspected to show strong non-statistical effects [9].

Due to the high reaction rates, these ligations can be used in time-critical applications such as rapid radiolabeling and pretargeted PET imaging [10-16] and provide high yields within short reaction times even at low concentrations as usually encountered in radiochemistry and in vivo. Therefore, kinetics is one of the most important characteristics of bioorthogonal reactions. However, prediction of reactivities using the chemist's understanding of organic chemistry, especially of IEDDA reactions, might lead to wrong predictions [17] and only qualitative estimates. In addition, synthesis of tetrazines is often low yielding and involves handling or even requires the production of anhydrous hydrazine (not commercially available in Europe), which limits the feasibility of screening for high Diels-Alder reactivity. Hence, there is the need of reliable computational tools to predict the reactivity of various tetrazines in TLs.

Herein, we introduce a computational model for the prediction of the reactivity of aryl/alkyl-substituted $\mathrm{Tz}$ in the cycloaddition with trans-cyclooctene (TCO), thus 


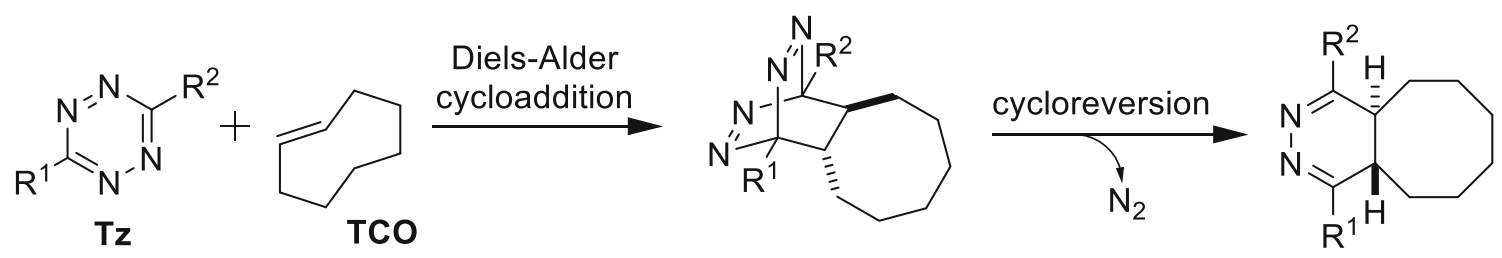

Fig. 1 Mechanism of the bioorthogonal ligation of 1,2,4,5-tetrazine (Tz) and trans-cyclooctene (TCO)

eliminating the need for expensive and even dangerous synthetic work, finally enabling in silico screening for tetrazines with desired reactivity.

While 3,6-bisaryl- and 3-aryl-substituted Tz show the highest reactivity, aryl/alkyl-substituted $\mathrm{Tz}$ are commonly used due to higher stability [18, 19] and show favorable properties in Tz-triggered bioorthogonal elimination reactions [20, 21].

\section{Results and discussion}

Recently, we have investigated the reactivity of several 3-aryl-6-(3-fluoropropyl)-1,2,4,5-tetrazines 1-8 as chemical probes for rapid radiolabeling and pretargeted PET<smiles>FCCCc1nnc(-c2ccccc2)nn1</smiles>

1<smiles>Cc1ccc(-c2nnc(CCCF)nn2)cc1</smiles>

2<smiles>COc1cc(-c2nnc(CCCF)nn2)cc(OC)c1OC</smiles>

3<smiles>FCCCc1nnc(-c2ccc(C(F)(F)F)cc2)nn1</smiles>

4

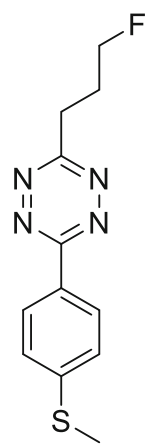

5<smiles>CS(=O)c1ccc(-c2nnc(CCCF)nn2)cc1</smiles>

6

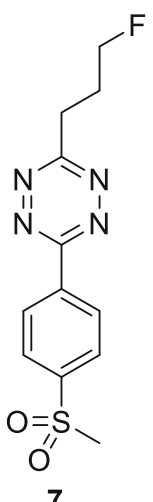

7

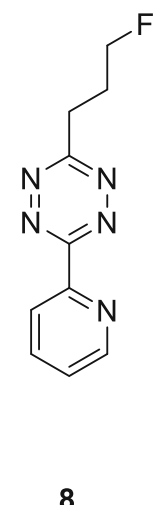

8

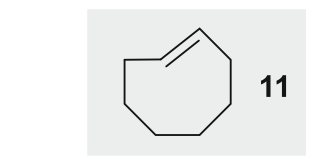

Fig. 2 Investigated aryl/alkyl substituted 1,2,4,5-tetrazines in the IEDDA reaction with trans-cyclooctene (11) imaging (Fig. 2). While the alkyl substituent is the same for all eight tetrazines the aryl component shows considerable variation including electron-rich and electron-poor aryl groups. In addition, $\mathrm{Tz} \mathbf{9}$ and $\mathbf{1 0}$ were included to investigate the influence of the alkyl group and an orthosubstituted aryl residue, respectively.

The second-order rate constants of $\mathrm{Tz} \mathbf{1 - 1 0}$ in the reaction with trans-cyclooctene 11 at $25^{\circ} \mathrm{C}$ in anhydrous 1,4-dioxane were measured by stopped-flow spectrophotometry, which gave rates ranging from $1.00 \mathrm{M}^{-1} \mathrm{~s}^{-1}$ for electron-rich trimethoxyphenyl-substituted $\mathrm{Tz} \quad 3$ to 14.6 $\mathrm{M}^{-1} \mathrm{~s}^{-1}$ for $\mathrm{Tz} 8$ bearing an electron withdrawing 2-pyridyl substituent (Fig. 3).

These experimental results were selected as a basis for the construction of a predictive computational tool. DFT was successfully used in the past by our group [16, 22] and others $[7,17,23,24]$ to predict or explain the reactivity of dienophiles and tetrazines in the tetrazine ligation. Therefore, the Minnesota density functional M06-2X in combination with the $6-311+\mathrm{G}(\mathrm{d}, \mathrm{p})$ basis set, was used as model chemistry. This density functional has been proven to produce accurate results for thermodynamics of cycloaddition reactions $[25,26]$.

Diels-Alder reactions can be described by $\mathrm{HOMO} /$ LUMO interactions using the frontier molecular orbital (FMO) theory. In case of the IEDDA cycloaddition the main orbital interaction is between a low-lying unoccupied orbital of the dienophile, usually being the LUMO+1 for aryl/alkyl tetrazines (Fig. 4a) [17], and the HOMO of the electron-rich dienophile (in this case TCO, Fig. 4b).

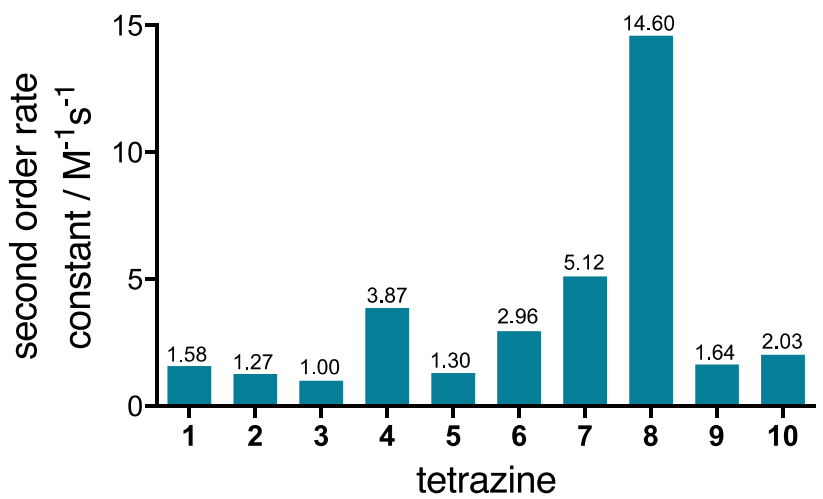

Fig. 3 Second-order rate constants of tetrazines 1-10 with transcyclooctene (11) in 1,4-dioxane at $25^{\circ} \mathrm{C}$ 
Fig. 4 a HOMO, LUMO, and LUMO+1 of 3-methyl-6phenyl-Tz (9); b HOMO of TCO (11); c energy levels of selected orbitals for tetrazines 1-10 and TCO (11)
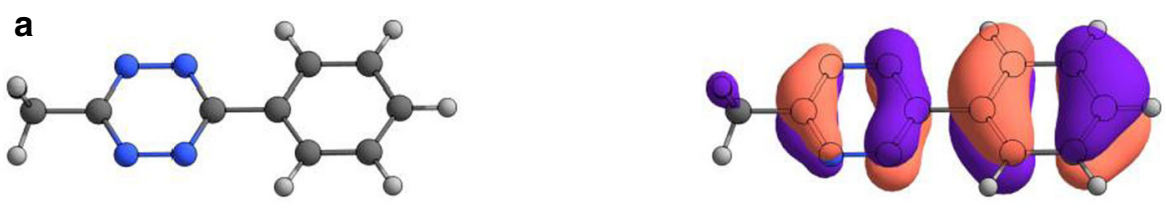

LUMO

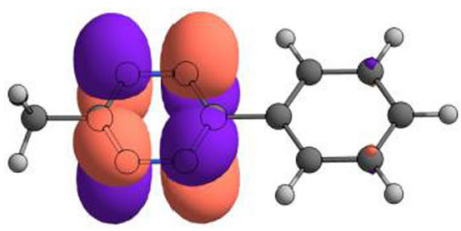

HOMO

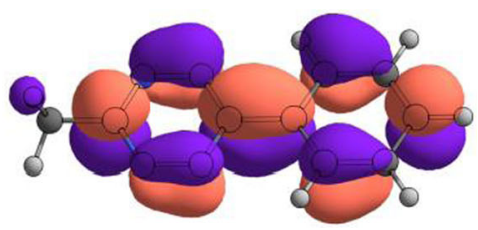

LUMO+1 b

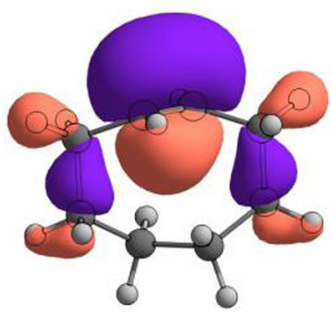

HOMO

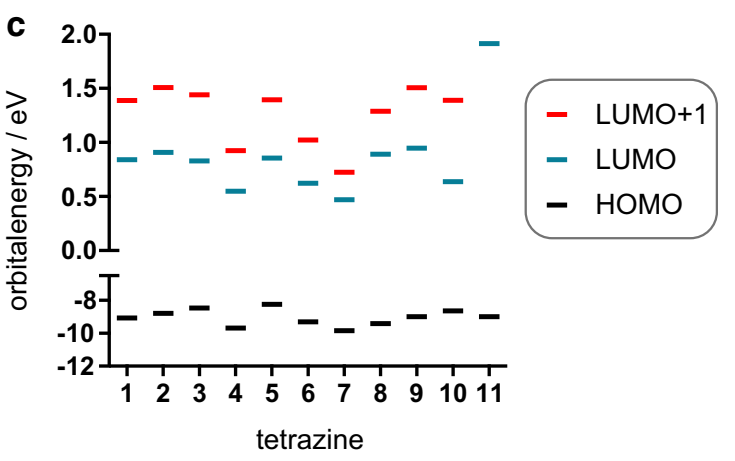

According to the FMO theory, a smaller energy gap between the interacting orbitals facilitates the reaction. Thus, one might expect that a more electron withdrawing and thus LUMO+1-lowering substituent accelerates the reaction, while an electron-rich aryl substituent will decrease reactivity. HF/6-311+G(d,p)//M06-2X/6$311+\mathrm{G}(\mathrm{d}, \mathrm{p})$-calculated orbital energies are shown in Fig. 4c. Tz 4 and 7 bearing an electron-withdrawing trifluoromethyl or sulfone group, respectively, show the lowest LUMO and LUMO +1 energies. However, the tetrazine with the highest reactivity, $\mathrm{Tz} \mathbf{8}$, has one of the highest LUMO and a rather high LUMO+1 energy within the series. As shown in Fig. 5, there is no significant

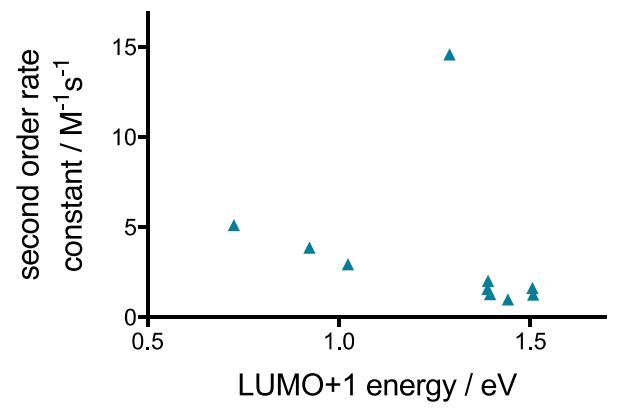

Fig. 5 Second-order rate constants plotted against HF/6$311+\mathrm{G}(\mathrm{d}, \mathrm{p}) / / \mathrm{M} 06-2 \mathrm{X} / 6-311+\mathrm{G}(\mathrm{d}, \mathrm{p})$ calculated LUMO+1 energies of the corresponding tetrazine correlation between the LUMO+1-energy levels and the rate constants $\left(R^{2}=0.07\right)$. This can be rationalized by the fact that FMO interactions are not the only major contributors to activation energies in such cycloadditions [17, 27-29]. Therefore, the FMO theory cannot be applied for the reliable prediction of the Diels-Alder reactivity of aryl/alkyl-substituted Tz.

However, the calculated energies of activation $\left(\Delta E^{\ddagger}\right)$ of the reactions between tetrazines 1-10 and TCO (11) show excellent linear correlation with the natural logarithm of the measured rate constants, as per transition state theory (Fig. 6). M06-2X/6-311+G(d,p) calculated energies of

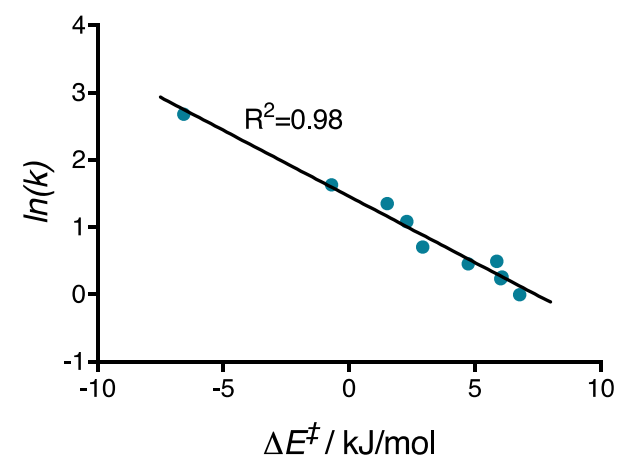

Fig. 6 Correlation between natural logarithm of second-order rate constants and M06-2X/6-311+G(d,p) calculated energies of activation 
activation can, therefore, be used to reliably predict the reactivity of aryl/alkyl-Tz in IEDDA reactions with transcyclooctenes.

Using the linear correlation between $\ln (k)$ and calculated $\Delta E^{*}$, Eq. (1) can be constructed which allows the prediction of the rate constant of new aryl/alkyl-Tz for the reaction with TCO (11) in anhydrous 1,4-dioxane at $25^{\circ} \mathrm{C}$.

$k=\mathrm{e}^{-0.1963 * \Delta E^{\ddagger}+1.460}$

\section{Conclusion}

Prediction of the reactivity of $\mathrm{Tz}$ in bioorthogonal ligation reactions is essential to reduce synthetic work, the resulting costs and associated risks. However, the chemist's prediction of these reactivities, mainly based on frontier molecular orbital theory, can only yield qualitative or even wrong results as shown in this work. We were able to develop a computational method for the prediction of reactivities of aryl/alkyl-substituted 1,2,4,5-tetrazines in the reaction with trans-cyclooctene based on M06-2Xcalculated energies of activation. This method is computationally cheap as it requires only the optimization of the tetrazine and the corresponding transition state with transcyclooctene at the M06-2X/6-311+G(d,p) level of theory, which can even be done on an average desktop PC within hours.

We are convinced that our method will aid the development of new aryl/alkyl tetrazines for bioorthogonal applications, and represents a step forward to the development of a universal computational tool being able to predict the reactivity of tetrazines with various substitution patterns.

\section{Experimental}

\section{Computational methods}

Calculations were performed at the M06-2X/6-311+G(d,p) level of theory in the gas phase using the Gaussian 09 Rev. D.01 software package [30]. Vibrational analysis was performed to confirm stationary points are energetic minima or transition states, respectively. Orbital energies were calculated by performing a $\mathrm{HF} / 6-311+\mathrm{G}(\mathrm{d}, \mathrm{p})$ single-point calculation on M06-2X/6-311+G(d,p) optimized structures. $\Delta E^{\ddagger}$ was determined by calculating the difference in energies between transition state and reactants. Data analysis was preformed using Gaussview 5 and Chemcraft. XYZ coordinate files of all reactants and transition states are available as electronic supplementary material. Calculated
Table 1 Calculated total electronic energies of compounds 1-11 and transition states for the reaction between 1-10 and 11, and calculated energies of activation $\left(\Delta E^{*}\right)$

\begin{tabular}{lccl}
\hline Compound & $E(\mathrm{Tz}) / \mathrm{hartree}$ & $E(\mathrm{TS}) /$ hartree & $\Delta E^{\ddagger} / \mathrm{kJ} \mathrm{mol}^{-1}$ \\
\hline $\mathbf{1}$ & -744.464487 & -1057.63536 & 4.74 \\
$\mathbf{2}$ & -783.771996 & -1096.942379 & 6.02 \\
$\mathbf{3}$ & -1087.994366 & -1401.164459 & 6.78 \\
$\mathbf{4}$ & -1081.515706 & -1394.687804 & 1.52 \\
$\mathbf{5}$ & -1181.953194 & -1495.123556 & 6.08 \\
$\mathbf{6}$ & -1257.12132 & -1570.293123 & 2.29 \\
$\mathbf{7}$ & -1332.328085 & -1645.501028 & -0.70 \\
$\mathbf{8}$ & -760.498963 & -1073.674144 & -6.57 \\
$\mathbf{9}$ & -566.619295 & -879.789737 & 5.87 \\
$\mathbf{1 0}$ & -641.851471 & -955.023032 & 2.93 \\
TCO (11) & -313.172677 & - & - \\
\hline
\end{tabular}

energies for $\mathrm{Tz} \mathbf{1}-\mathbf{1 0}$ and the respective transition states (for the reaction with TCO) are shown in Table 1.

\section{Synthesis}

Trans-cyclooctene (11) and tetrazines 9 and $\mathbf{1 0}$ were prepared following known procedures [31, 32]. The synthesis of compounds 1-8 will be published elsewhere (manuscript in preparation).

\section{Kinetic measurements}

Kinetic measurements were performed on a SX20 stoppedflow spectrophotometer (Applied Photophysics, UK) using a $535 \mathrm{~nm}$ LED light source. A $4 \mathrm{mM}$ solution of $\mathbf{1 1}$ and approximately $0.1 \mathrm{mM}$ solutions of $\mathrm{Tz} \mathbf{1}-\mathbf{1 0}$ were prepared in anhydrous 1,4-dioxane (note: for correct measurements it is of utmost importance to use anhydrous 1,4-dioxane,

Table 2 Observed rate constants, concentrations of TCO (11) and the corresponding $\mathrm{Tz}$, and calculated second-order rate constants of the IEDDA reaction between $\mathrm{Tz} \mathbf{1}-\mathbf{1 0}$ and $\mathbf{1 1}$

\begin{tabular}{llllc}
\hline Reaction & $k_{\text {obs }} / \mathrm{s}^{-1}$ & $c_{\mathrm{TCO}} / \mathrm{M}$ & $c_{\text {tetrazine }} / \mathrm{M}$ & $k / \mathrm{M}^{-1} \mathrm{~s}^{-1}$ \\
\hline $\mathbf{1}+\mathbf{1 1}$ & 0.003278 & 0.002081 & 0.000064 & 1.58 \\
$\mathbf{2}+\mathbf{1 1}$ & 0.002652 & 0.002096 & 0.00005 & 1.27 \\
$\mathbf{3}+\mathbf{1 1}$ & 0.00205 & 0.002051 & 0.000049 & 1.00 \\
$\mathbf{4}+\mathbf{1 1}$ & 0.007801 & 0.002015 & 0.00005 & 3.87 \\
$\mathbf{5}+\mathbf{1 1}$ & 0.002703 & 0.002081 & 0.000034 & 1.30 \\
$\mathbf{6}+\mathbf{1 1}$ & 0.005811 & 0.00196 & 0.000046 & 2.96 \\
$\mathbf{7}+\mathbf{1 1}$ & 0.009894 & 0.001933 & 0.000103 & 5.12 \\
$\mathbf{8}+\mathbf{1 1}$ & 0.03064 & 0.002096 & 0.00005 & 14.6 \\
$\mathbf{9}+\mathbf{1 1}$ & 0.00461 & 0.002813 & 0.000058 & 1.64 \\
$\mathbf{1 0}+\mathbf{1 1}$ & 0.004514 & 0.002224 & 0.000061 & 2.03 \\
\hline
\end{tabular}


since even small amounts of water will accelerate the reaction, leading to irreproducible data). These solutions were loaded into the driver syringes and equal volumes of $\mathrm{TCO}$ and Tz solution were mixed, resulting in concentrations of 2 and $0.05 \mathrm{mM}$, respectively. The reaction progress was followed by measuring the absorption around $535 \mathrm{~nm}$. All measurements were performed in triplicates. Observed reaction constants $\left(k_{\text {obs }}\right)$ were determined by non-linear regression (one-phase-decay) using Prism 6 (Graphpad) and second-order rate constants $(k)$ were calculated from $k_{\mathrm{obs}}$. Table 2 lists $k_{\mathrm{obs}}, c_{\mathrm{TCO}}, c_{\mathrm{Tz}}$ and $k$ for all reactions.

Acknowledgements Open access funding provided by TU Wien (TUW). The authors thank Heidi Fittner (TU Wien) for her support. Quantum-chemical calculations were performed using the Vienna Scientific Cluster (VSC). This project has received funding from the European Union's Horizon 2020 research and innovation programme under Grant Agreement No 668532 ('Click-It').

Open Access This article is distributed under the terms of the Creative Commons Attribution 4.0 International License (http:// creativecommons.org/licenses/by/4.0/), which permits unrestricted use, distribution, and reproduction in any medium, provided you give appropriate credit to the original author(s) and the source, provide a link to the Creative Commons license, and indicate if changes were made.

\section{References}

1. Darko A, Wallace S, Dmitrenko O, Machovina MM, Mehl RA, Chin JW, Fox JM (2014) Chem Sci 5:3770

2. Devaraj NK, Weissleder R, Hilderbrand SA (2008) Bioconjug Chem 19:2297

3. Knall A-C, Hollauf M, Slugove C (2014) Tetrahedron Lett $55: 4763$

4. Yang J, Šečkute J, Cole CM, Devaraj NK (2012) Angew Chem Int Ed 51:7476

5. Yang J, Liang Y, Šečkutė J, Houk KN, Devaraj NK (2014) Chemistry 20:3365

6. Rossin R, van den Bosch SM, Ten Hoeve W, Carvelli M, Versteegen RM, Lub J, Robillard MS (2013) Bioconjug Chem 24:1210

7. Taylor MT, Blackman ML, Dmitrenko O, Fox JM (2011) J Am Chem Soc 133:9646

8. Selvaraj R, Fox JM (2013) Curr Opin Chem Biol 17:753

9. Törk L, Jiménez-Osés G, Doubleday C, Liu F, Houk KN (2015) J Am Chem Soc 137:4749

10. Wang M, Svatunek D, Rohlfing K, Liu Y, Wang H, Giglio B, Yuan H, Wu Z, Li Z, Fox J (2016) Theranostics 6:887

11. Wu Z, Liu S, Hassink M, Nair I, Park R, Li L, Todorov I, Fox JM, Li Z, Shively JE, Conti PS, Kandeel F (2013) J Nucl Med 54:244
12. Rossin R, van Duijnhoven SMJ, van den Bosch SM, Robillard MS (2014) Nucl Med Biol 41:630

13. Li Z, Cai H, Hassink M, Blackman ML, Brown RCD, Conti PS, Fox JM (2010) Chem Commun 46:8043

14. Liu S, Hassink M, Selvaraj R, Yap L, Park R, Wang H, Chen X, Fox JM, Li Z, Conti PS (2013) Mol Imaging 12:121

15. Meyer JP, Houghton JL, Kozlowski P, Abdel-Atti D, Reiner T, Pillarsetty NVK, Scholz WW, Zeglis BM, Lewis JS (2016) Bioconjug Chem 27:298

16. Denk C, Svatunek D, Filip T, Wanek T, Lumpi D, Fröhlich J, Kuntner C, Mikula H (2014) Angew Chem Int Ed 53:9655

17. Liu F, Liang Y, Houk KN (2014) J Am Chem Soc 136:11483

18. Carlson JCT, Meimetis LG, Hilderbrand SA, Weissleder R (2013) Angew Chem Int Ed 52:6917

19. Karver MR, Weissleder R, Hilderbrand SA (2011) Bioconjug Chem 22:2263

20. Fan X, Ge Y, Lin F, Yang Y, Zhang G, Ngai WSC, Lin Z, Zheng S, Wang J, Zhao J, Li J, Chen PR (2016) Angew Chem Int Ed 55:14046

21. Rossin R, van Duijnhoven SMJ, ten Hoeve W, Janssen HM, Kleijn LHJ, Hoeben FJM, Versteegen RM, Robillard MS (2016) Bioconjug Chem 27:1697

22. Denk C, Svatunek D, Mairinger S, Stanek J, Filip T, Matscheko D, Kuntner C, Wanek T, Mikula H (2016) Bioconjug Chem 27:1707

23. Liang Y, Mackey JL, Lopez S, Liu F, Houk KN (2012) J Am Chem Soc 134:17904

24. Lambert WD, Scinto SL, Dmitrenko O, Boyd SJ, Magboo R, Mehl RA, Chin JW, Fox JM, Wallace S (2017) Org Biomol Chem 15:6640

25. Lan Y, Zou L, Cao Y, Houk KN (2011) J Phys Chem A 115:13906

26. Paton RS, Mackey JL, Kim WH, Lee JH, Danishefsky SJ, Houk KN (2010) J Am Chem Soc 132:9335

27. Levandowski BJ, Houk KN (2015) J Org Chem 80:3530

28. Liu F, Paton RS, Kim S, Liang Y, Houk KN (2013) J Am Chem Soc 135:15642

29. Levandowski BJ, Hamlin TA, Bickelhaupt FM, Houk KN (2017) J Org Chem 82:8668

30. Frisch MJ, Trucks GW, Schlegel HB, Scuseria GE, Robb MA, Cheeseman JR, Scalmani G, Barone V, Petersson GA, Nakatsuji H, Li X, Caricato M, Marenich A, Bloino J, Janesko BG, Gomperts $\mathrm{R}$, Mennucci $\mathrm{B}$, Hratchian HP, Ortiz JV, Izmaylov AF, Sonnenberg JL, Williams-Young D, Ding F, Lipparini F, Egidi F, Goings J, Peng B, Petrone A, Henderson T, Ranasinghe D, Zakrzewski VG, Gao J, Rega N, Zheng G, Liang W, Hada M, Ehara M, Toyota K, Fukuda R, Hasegawa J, Ishida M, Nakajima $\mathrm{T}$, Honda Y, Kitao O, Nakai H, Vreven T, Throssell K, Montgomery Jr JA, Peralta JE, Ogliaro F, Bearpark M, Heyd JJ, Brothers E, Kudin KN, Staroverov VN, Keith T, Kobayashi R, Normand J, Raghavachari K, Rendell A, Burant JC, Iyengar SS, Tomasi J, Cossi M, Millam JM, Klene M, Adamo C, Cammi R, Ochterski JW, Martin RL, Morokuma K, Farkas O, Foresman JB, Fox DJ (2016) Gaussian 09, Rev. D.01. Gaussian Inc., Wallingford

31. Svatunek D, Denk C, Rosecker V, Sohr B, Hametner C, Allmaier G, Fröhlich J, Mikula H (2016) Monatsh Chem 147:579

32. Suh S-E, Barros SA, Chenoweth DM (2015) Chem Sci 6:5128 